\title{
An Exploratory Analysis of Anesthesia Related Barriers to Breastfeeding Success in Patients after Cesarean Section
}

\author{
Samantha J Bido*, Richard Henker, Grace Lim, Nicholas G Bircher and Jill R Demirci \\ University of Pittsburgh, USA
}

Submission: January 07, 2020; Published: January 21, 2020

*Corresponding author: Samantha J Bido, University of Pittsburgh, USA

\begin{abstract}
Background: Breastfeeding yields numerous benefits for both the mother and child. Yet, women who undergo cesarean sections have consistently lower rates of breastfeeding initiation and continuation. There is some evidence that pruritis and nausea/vomiting, mainly related to anesthesia, may be contributing factors.

Objectives: To identify anesthesia-related barriers to breastfeeding success in patients after cesarean section with a focus on the impact of nausea/vomiting

Methods: We surveyed women at 6-12 months postpartum about their breastfeeding experiences after cesarean section delivery. Women were selected via previous participation in the ParlaiQ Digital Rounding assessment. This assessment was a primary analysis of nausea and vomiting frequency in this population conducted by the hospital's nursing team. We also conducted a retrospective chart review for all study participants during their birth hospitalization to examine demographic, anesthetic, and surgical factors. The association of factors with our primary outcome (success in breastfeeding) and secondary outcome (nausea/vomiting) was assessed using Fisher's Exact test for categorical variables. The factors determined from surveys and chart review were analyzed to determine potential anesthetic related barriers to breastfeeding success, with a focus on the problem of anesthetic induced nausea and vomiting. The surveys and chart review were quantitatively and qualitatively analyzed to determine potential anesthetic related barriers to breastfeeding success, with a focus on the problem of anesthetic induced nausea and vomiting. For the purposes of this analysis, success was defined as the mother's perception of initiating breastfeeding without trouble or delay.

Result: Thirty-two women were included in the study; 69\% (22/32) experienced nausea/vomiting either during or after their cesarean section. There were trends toward an association of nausea/vomiting and being African American, receiving neuraxial fentanyl during the cesarean section and receiving neuraxial anesthesia for the cesarean section. Of the 26 women who intended to breastfeed, 16 reported success (62\%) Problems with latching were identified as the biggest barrier to breastfeeding success (42.9\% 6/14 of women cited as barrier). Working with the lactation consultant was identified most often as a facilitator to breastfeeding success $(43.5 \%, 10 / 23$ women cited as a facilitator).

Conclusion: Anesthesia providers are responsible for attempting to control the high rates of nausea/vomiting in women during cesarean section as well as providing pain relief that lasts longer into the postoperative period. In an effort to increase breastfeeding success in the cesarean populations, mothers with the intent to breastfeed, who have identified risk factors for breastfeeding failure should be visited by the lactation specialist after birth. Further research is needed to identify risk factors and ways in which anesthetic interventions can be tailored to optimize chances for successful breastfeeding.
\end{abstract}

Keywords: Anesthesia; Breastfeeding; Cesarean section; Nausea/vomiting

\section{Introduction}

Breastfeeding is associated with health benefits to both the mother and child, and when viewed as a public health intervention, it is both highly effective and relatively inexpensive. The breastfed child has a lowered risk of contracting several communicable childhood illnesses and is less likely to become obese or develop cardiovascular morbidity as an adult [1]. The breastfeeding mother may experience lower risk of bleeding after birth and a lower incidence of type II diabetes, breast, and ovarian cancer [1].
Although controversial, the literature suggests that women who undergo cesarean delivery experience delays in breastfeeding initiation and are less likely to continue to breastfeed compared to women who have non-operative, vaginal deliveries [1]. Barriers to breastfeeding after cesarean may include maternal/ infant separation; reduced infant suckling and receptivity to the breast due to effects of anesthetics, medical complications, and insufficient milk supply related to delays and interruptions 
in breastfeeds. [1,2]. Ultimately, Pérez-Ríos [3] explains that "aggravated health outcomes can compromise the mother's ability to breastfeed, not only by prolonging maternal- infant separation, but also by forcing mothers to concentrate more on their recovery, rather than on their baby's nutritional needs," [3].

Analgesics used during cesarean often result in postoperative nausea and vomiting (PONV), pruritus, and maternal sedation which may negatively impact early attempts at breastfeeding and delay onset of lactogenesis II (copious milk production typically occurring at 2-4 days postpartum). The estimated incidence of nausea and vomiting alone is as high as $50-80 \%$ in women receiving a cesarean under spinal anesthesia without prophylactic vasopressor therapies during and after the intraoperative [4]. In addition to analgesic use, increased intra-gastric pressure, hypotension, exteriorization of the uterus, excessive surgical manipulation and visceral stimulation, uterotonic agents, and the patient's mental status all contribute to the high incidence of nausea and vomiting in this population [5].

Our institutional observation is that post-cesarean pruritus and nausea/vomiting contributes to poor breastfeeding initiation. Therefore, we undertook this project to identify anesthesia related barriers to breastfeeding success in patients after cesarean section with a focus on the impact of nausea and vomiting. Specific aims of the study included [6]

a) Determine the frequency of IONV/PONV in women undergoing cesarean delivery

b) Identify risk factors associated with IONV/PONV in women undergoing cesarean delivery

c) Understand the impact of anesthesia related barriers, specifically nausea and vomiting, on breastfeeding success in patients after cesarean delivery.

\section{Materials and Methods}

This exploratory descriptive analysis was conducted at UPMC Magee Women's Hospital, a National Center of Excellence in Women's Health, with nearly 10,000 deliveries annually. The project leader gained approval from the Obstetrical director of Magee in addition to DNP board approval and Magee Quality Improvement Committee approval [7].

\section{Sample}

We surveyed women, who met the inclusion criteria, 6-12 months postpartum about their breastfeeding experiences after cesarean section delivery. Inclusion criteria were as follows: Women ages 18 years and above that underwent a cesarean within the study period (August-December 2018) and were previously surveyed for the ParlaiQ Digital Rounding assessment. Exclusion criteria were as follows: Women below the age of 18 years that underwent a cesarean outside of the study period
(August-December 2018) and/or not previously surveyed for the ParlaiQ Digital Rounding assessment. The ParlaiQ Digital Rounding assessment was a primary analysis of nausea and vomiting frequency in this population conducted previously by the hospital's nursing team. All data gathered during our analysis were collected outside and independent of the data collection of the ParlaiQ Digital Rounding assessment [8].

\section{Procedures}

The project leader performed a retrospective chart review that included analysis of items such as the demographic characteristics (Table 1), type of anesthetic, drug dosage and administration, and sex of the baby. The project leader then used Qualtrics survey system to survey the women, initially by phone. then via text message or email. The first 14 surveys were entered by the primary investigator via phone call. After multiple failed phone call attempts due to respondents not answering, text links and one email link were sent out to the remaining 18 respondents who then entered their answers themselves via the link sent. After the first 14 surveys were received the project committee analyzed the data and added or adjusted questions as needed. This survey question change accounted for missing data regarding some questions not answered by participants. The final survey addressed frequency of nausea/vomiting via a yes/no question, severity of nausea/ vomiting via a 10 point Likert scale, open ended patient identified greatest contributor to nausea/vomiting, average pain score after childbirth via a 10 point Likert scale, breastfeeding intention via a yes/no question, frequency of trouble or delay initiating breastfeeding via a yes/no question, extent of breastfeeding interference from several factors (a. nausea/vomiting, b. itchiness, c. pain, d. sleepiness/fatigue), on a 10 point Likert scale, open ended patient identified number one reason for difficulty, and open ended patient identified number one facilitator. Surveys and chart reviews were linked with a unique patient identifier and deidentified. Data were coded and entered into SPSS software for statistical analysis.

\section{Statistical Analysis}

The primary outcome for this study was successful breastfeeding. Secondary outcomes were nausea/vomiting and pain score. All continuous variables were tested for normal distribution using the Kolmogorov-Smirnov test, and either a t-test or the Mann-Whitney U test used as appropriate. Pairwise collinearity was estimated for continuous variables using linear regression and overall collinearity was assessed by calculating the variance inflation factor. For selected predictors of successful breastfeeding or nausea/vomiting, effect sizes were estimated using univariate logistic regression models. Statistical analysis was performed using SPSS 26 (IBM Corporation, Armonk, New York). Observed power computations and sample size estimates were calculated using PASS 16 (NCSS, LLC, Kaysville, Utah). 


\section{Result}

Demographic variables for study patients are liasted in Table 1. In our sample, $69 \%(22 / 32)$ of women experienced nausea and vomiting. There was a trend toward between experiencing nausea and vomiting and being African American 100\% (4/4), receiving neuraxial fentanyl $78 \%(21 / 27)$, and receiving neuraxial

Table 1: Characteristics of Study Population.

\begin{tabular}{|c|c|c|}
\hline Factor & Category Or Measure & \\
\hline $\mathrm{N}$ & & 32 \\
\hline \multicolumn{3}{|l|}{ Demographic } \\
\hline Age & Mean \pm SD & $31.8 \pm 4.4$ \\
\hline \multirow[t]{2}{*}{ Race } & Caucasian & 28 (87.5\%) \\
\hline & African American & $4(12.5 \%)$ \\
\hline \multirow[t]{2}{*}{ Smoker } & No & $30(93.8 \%)$ \\
\hline & Yes & $2(6.3 \%)$ \\
\hline \multirow[t]{2}{*}{ Parity } & Primiparous & $11(34.4 \%)$ \\
\hline & Multiparous & $21(65.6 \%)$ \\
\hline \multicolumn{3}{|l|}{ Anesthetic } \\
\hline \multirow[t]{4}{*}{ Anesthesia Type } & Spinal & $17(53.1 \%)$ \\
\hline & Epidural & $12(37.5 \%)$ \\
\hline & General & $2(6.3 \%)$ \\
\hline & CSE & $1(3.1 \%$ \\
\hline \multirow{2}{*}{ Duramorph } & Yes & $30(93.8 \%)$ \\
\hline & No & $2(.06 \%)$ \\
\hline \multirow[t]{2}{*}{ Fentanyl } & Yes & $13(40.6 \%)$ \\
\hline & No & $19(59.4 \%)$ \\
\hline \multirow[t]{2}{*}{ Nausea/Vomiting } & Yes & $22(68.8 \%)$ \\
\hline & No & $10(31.3 \%)$ \\
\hline N/V Severity & Median (IQR) & $7(5)$ \\
\hline Pain Score & Mean \pm SD & $5.8 \pm 2.2$ \\
\hline \multicolumn{3}{|l|}{ Operative/Other } \\
\hline \multirow[t]{2}{*}{ Operation } & Scheduled & $20(62.5 \%)$ \\
\hline & Emergent & $12(37.5 \%)$ \\
\hline EBL, ml. & Median (IQR) & $686.5(313)$ \\
\hline \multirow[t]{4}{*}{ EBL category } & $0-499 \mathrm{~mL}$ & $5(15.6 \%)$ \\
\hline & $500-999 \mathrm{ml}$ & $20(62.5 \%)$ \\
\hline & $1000-1499 \mathrm{~mL}$ & $6(18.8 \%)$ \\
\hline & $1500-1999 \mathrm{~mL}$ & $1(3.1 \%)$ \\
\hline \multirow[t]{2}{*}{ Sex of Baby } & Female & $15(46.9 \%)$ \\
\hline & Male & $17(53.1 \%)$ \\
\hline
\end{tabular}

$E B L=$ Estimated Blood Loss, CSE=combined spinal-epidural, N/V=Nausea and vomiting anesthesia 77\% (23/30). Initial breastfeeding success in the overall cesarean population was $50 \%(16 / 32)$. Of the 26 women who intended to breastfeed, 16 reported success (62\%) Problems with latching $42.9 \%$ (6/14) was identified as the biggest barrier to breastfeeding success. Working with the lactation consultant $43.5 \%(10 / 23)$ was identified as the greatest facilitator to breastfeeding success (Figure 1\&2). 


\section{Journal of Gynecology and Women's Health}

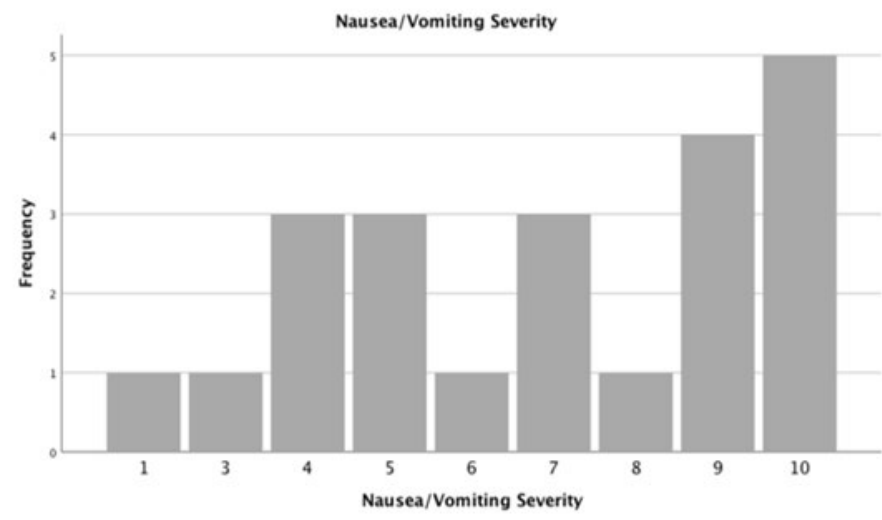

Figure 1: Nausea/Vomiting Severity

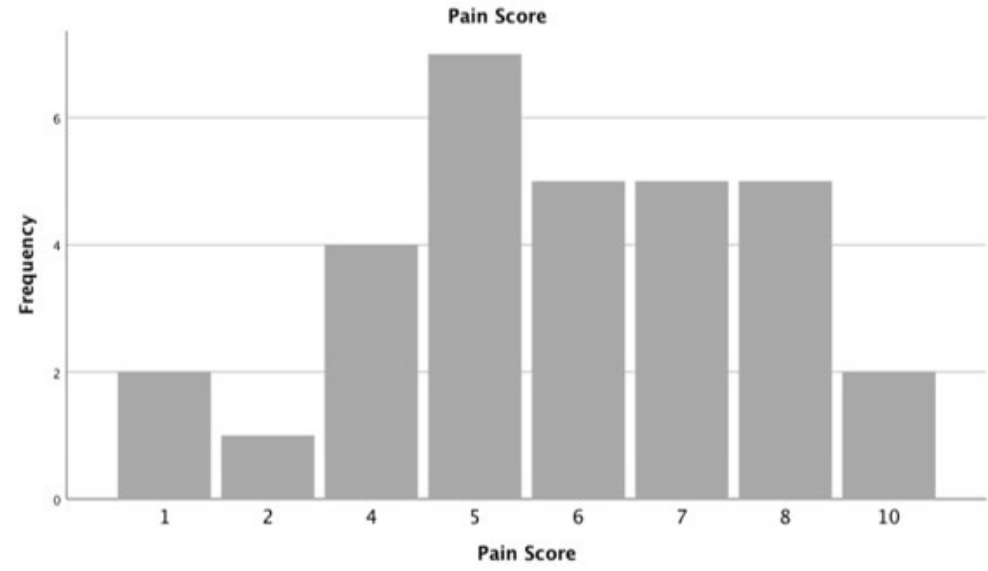

Figure 2: Average Pain Score After Birth

Anesthetic Factors

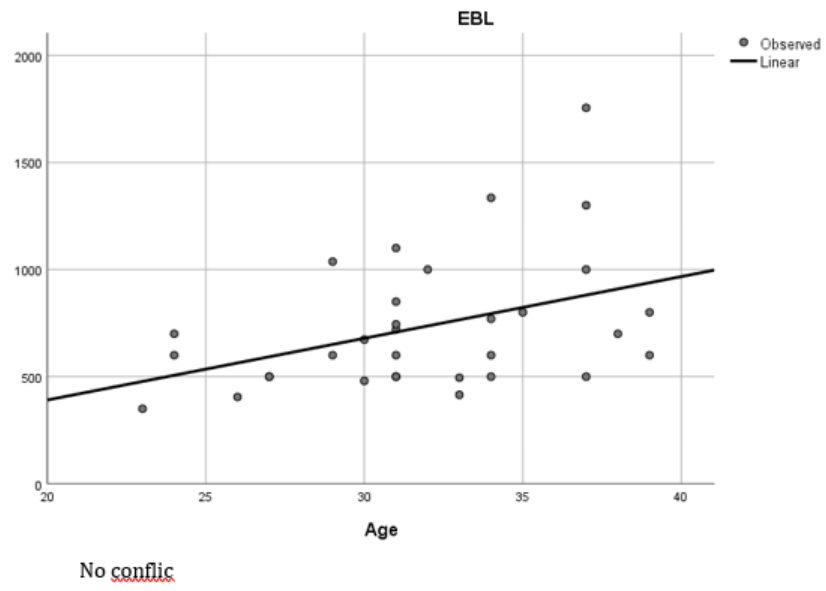

Figure 3: Association of maternal age with EBL 
There was also an association of anesthesia type with scheduled versus emergency cases ( $p=0.001$, Figure 3$)$.

\section{Operative and Other Factors}

There was an association between increasing maternal age and estimated blood loss ( $\mathrm{p}=0.023$, Figure 4\&5).

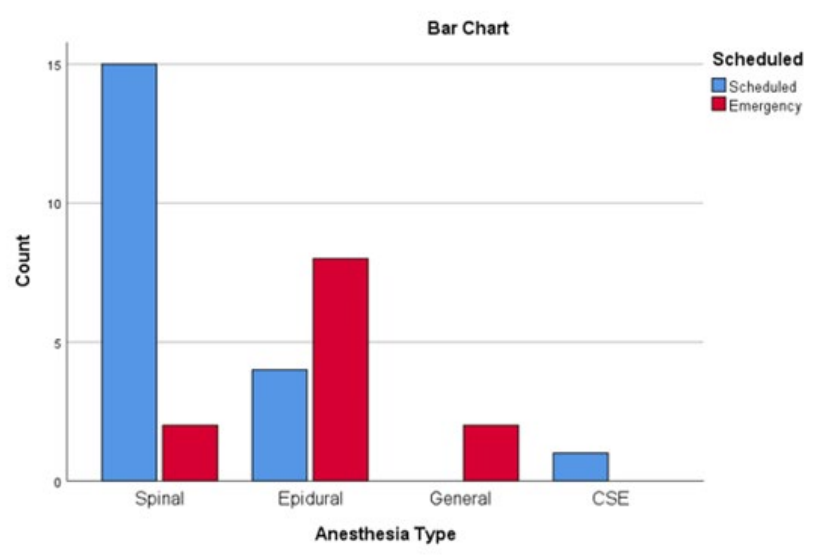

Figure 4: Association of Anesthesia Type with Scheduled versus Emergency Cases.

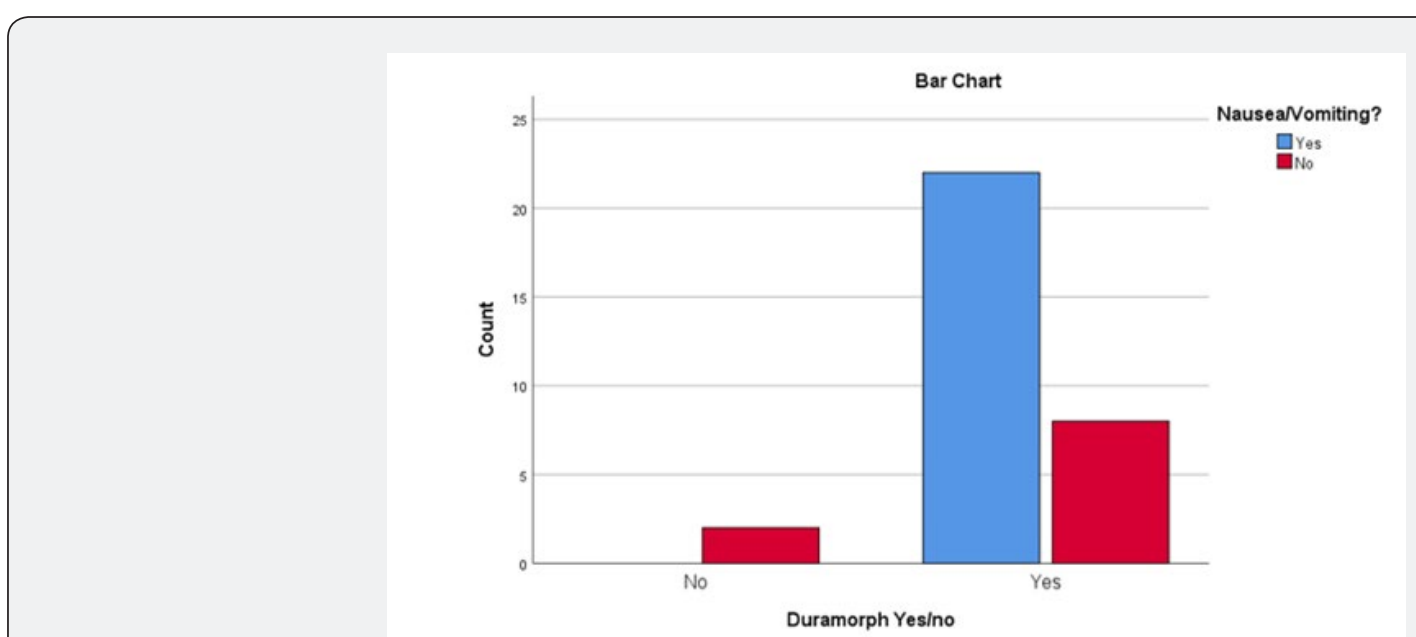

Figure 5: Association of Duramorph with nausea/vomiting.

\section{Discussion}

Strengths of the analysis include the mix of qualitative and quantitative data. Actual quotations from the participants provides a unique insight. The analysis also is a start in addressing the gap in the literature regarding the barriers to breastfeeding in post-operative cesarean mothers. Finally, the analysis provides a platform for further research. Further research could include addressing

a) further understanding of breastfeeding barriers/facilitators in patients after cesarean

b) ways to reduce incidence of nausea/vomiting in this

\section{population}

c) ways to increase initial breastfeeding success in this population

d) analysis of long-term breastfeeding success in this population (Table 2\&3).

Limitations include recall bias, surveying women 7-12 months after delivery. Another limitation is the lack of follow-up for analysis of long-term breast-feeding success in this population. Additionally, small sample size allows for identification of potential trends towards clinical significance but without statistical significance. 
Table 2: What do you believe most contributed to your nausea/vomiting?

\begin{tabular}{|c|c|}
\hline Category & Survey Response \\
\hline $\mathrm{N}$ & 11 \\
\hline \multirow[t]{8}{*}{ Anesthesia related } & “Anesthesia” 2 (18\%) \\
\hline & "Anxiety/fear" $1(9 \%)$ \\
\hline & "Food and medication combination" $1(9 \%)$ \\
\hline & “Too much medication in spinal/epidural” $1(9 \%)$ \\
\hline & "Rapid introduction of pain medication, I had an unplanned C" 1 (9\%) \\
\hline & "I get nauseous when twilighted" 1 (9\%) \\
\hline & "Positioning, lack of pre-medication prior to OR" $1(9 \%)$ \\
\hline & "Medication" $1(9 \%)$ \\
\hline Total & $9(82 \%)$ \\
\hline \multirow[t]{2}{*}{ Other } & "Not sure" 1 (9\%) \\
\hline & "Labor Process" 1 (9\%) \\
\hline Total & $2(18 \%)$ \\
\hline
\end{tabular}

Table 3: Barriers and Facilitators to Breastfeeding.

\begin{tabular}{|c|c|}
\hline Barriers & \\
\hline $\mathrm{N}$ & 14 \\
\hline Problems with latching & $6(18.8 \%)$ \\
\hline No milk production & $2(6.3 \%)$ \\
\hline Pain & $1(3.1 \%)$ \\
\hline Not seeing the lactation consultant soon enough & $1(3.1 \%)$ \\
\hline Lack of experience & $1(3.1 \%)$ \\
\hline Child in NICU & $1(3.1 \%)$ \\
\hline Nausea/vomiting & $1(3.1 \%)$ \\
\hline No lactation help & $1(3.1 \%)$ \\
\hline \multicolumn{2}{|l|}{ Facilitators } \\
\hline $\mathrm{N}$ & 23 \\
\hline Lactation consultant & $10(31.3 \%)$ \\
\hline Experience & $4(12.5 \%)$ \\
\hline Nurse/doula & $3(9.4 \%)$ \\
\hline Nothing & $2(6.3 \%)$ \\
\hline Pumping in addition & $1(3.1 \%)$ \\
\hline Relaxing/quiet atmosphere & $1(3.1 \%)$ \\
\hline Constantly trying & $1(3.1 \%)$ \\
\hline
\end{tabular}

$\mathrm{NICU}=$ Neonatal intensive care unit

\section{Conclusion}

Anesthesia providers have an opportunity to decrease rates of nausea/vomiting in this population. Anesthesia providers have an opportunity to provide better pain control in this population. All patients with the intent to breastfeed should be provided with a visit from the lactation consultant. 


\section{References}

1. Hobbs AJ, Mannion CA, McDonald SW, Brockway M, Tough SC, et al. (2016) The impact of caesarean section on breastfeeding initiation, duration and difficulties in the first four months postpartum. BMC Pregnancy Childbirth 16: 90.

2. Uerpairojkit K, Chesoh A, Budcharoentong D (2017) Ondansetron for Prophylaxis of Spinal Morphine Induced Nausea during Early Rooming in Breastfeeding: A Randomized Placebo Controlled Trial. J Med Assoc Thai100(12): 7.

3. Perez-Rios N, Ramos-Valencia G, Ortiz AP (2008) Cesarean delivery as a barrier for breastfeeding initiation: the Puerto Rican experience. J Hum Lact 24(3): 293-302.

4. Kavala A, Darji SJ, Kalstein A, Yarmush JM, SchianodiCola J, et al. (2013) Efficacy of ginger on intraoperative and postoperative nausea and vomiting in elective cesarean section patients. Eur J Obstet Gynecol Reprod Biol 169(2): 184-188.

5. Semiz A, Akpak YK, Yilanlioglu NC, Babacan A, Gonen G, et al. (2017) Prediction of intraoperative nausea and vomiting in caesarean delivery under regional anaesthesia. J Int Med Res 45(1): 332-339.

6. Mulder PJ (2006) A concept analysis of effective breastfeeding. J Obstet Gynecol Neonatal Nurs 35(3): 332-339.

7. Lane B, Cannella K, Bowen C, Copeland D, Nteff G, et al. (2012) Examination of the effectiveness of peppermint aromatherapy on nausea in women post C-section. J Holist Nurs 30(2): 90-104.

8. Griffiths J, Gyte G, Paranjothy S, Brown H, Broughton H, et al. (2012) Interventions for preventing nausea and vomiting in women undergoing regional anaesthesia for caesarean section. The Cochrane Collaboration 9: 1-224.

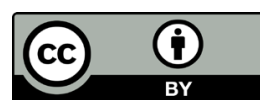

This work is licensed under Creative Commons Attribution 4.0 License DOI: 10.19080/JGWH.2020.18.555980

\section{Your next submission with Juniper Publishers will reach you the below assets}

- Quality Editorial service

- Swift Peer Review

- Reprints availability

- E-prints Service

- Manuscript Podcast for convenient understanding

- Global attainment for your research

- Manuscript accessibility in different formats

( Pdf, E-pub, Full Tsext, Audio)

- Unceasing customer service

Track the below URL for one-step submission https://juniperpublishers.com/online-submission.php 